\title{
Evolutionary Ecology of Lizards: Lessons from a Special Issue
}

\author{
Francisco Javier Zamora-Camacho ${ }^{1, *(\mathbb{D})}$ and Mar Comas ${ }^{2}$ \\ 1 Departamento de Biodiversidad, Ecología y Evolución, Facultad de Ciencias Biológicas, Universidad \\ Complutense de Madrid, C/José Antonio Novais 12, 28040 Madrid, Spain \\ 2 Departamento de Zoología, Facultad de Ciencias, Universidad de Granada, 18071 Granada, Spain; \\ marcomas@ugr.es \\ * Correspondence: zamcam@ugr.es
}

Citation: Zamora-Camacho, F.J.; Comas, M. Evolutionary Ecology of Lizards: Lessons from a Special Issue. Diversity 2021, 13, 565. https:// doi.org/10.3390/d13110565

Received: 11 October 2021

Accepted: 12 October 2021

Published: 5 November 2021

Publisher's Note: MDPI stays neutral with regard to jurisdictional claims in published maps and institutional affiliations.

Copyright: (c) 2021 by the authors. Licensee MDPI, Basel, Switzerland. This article is an open access article distributed under the terms and conditions of the Creative Commons Attribution (CC BY) license (https:// creativecommons.org/licenses/by/ $4.0 /)$.
Regardless of taxonomical disquisitions on its yet unraveled phylogenetic relationships within and among taxa [1], the Lacertilia constitute one of the most successful clades within vertebrates. With above 6000 extant species, not only have lizards (as these animals are broadly referred to in common parlance) undergone an outstanding degree of diversification, but this comes along with adaptations that allow them to thrive in most terrestrial habitats worldwide and occupy astonishingly diverse ecological niches [2]. With the exception of Antarctica, lizards are represented in all continents, where they can be found from the seashore to alpine elevations, in a wide array of habitats encompassing deserts, temperate and tropical forests, meadowy, sandy or rocky grounds, and virtually all terrestrial landscapes available [2].

However, not all these habitats are equally relevant in lizard evolutionary history and speciation processes. Although reproductive isolation is deemed one of the most important motors of speciation, the reality is more intricate than that, and involves other variables limiting or potentiating gene flow [3]. Ultimately, reproductive isolation cannot simplistically be regarded as categorical: factors affecting the actual degree of gene flow impairment, the recurrence of isolation events, and their persistence through time determine the probability of speciation to culminate [4]. Therefore, habitats that are structured into fragmented landscapes, capable of acting as ecological islands, can be especially prone to promote radiation. That is the case of karstic landscapes, which constitute a mosaic of isle-like fragments composed of caves, hills, and towers where crevices abound and provide multitude of microhabitats that might boost speciation. This prediction was confirmed by Grismer et al. [5] in this Special Issue. In their work, they analyzed habitat preferences of 344 Cyrtodactylus gecko species (one the most diverse genera within vertebrates, distributed in Asia and Oceania), accounting for a phylogenetic reconstruction of the clade using mitochondrial DNA [5]. They concluded that not only is the preference for karstic landscapes the norm, but it also represents the ancestral condition, which confirms karsts as a major trigger of lizard diversity [5].

Notably, diversity of species with similar ecological requirements may result in conflicting forces for spatial distribution. According to contemporary niche theory, populational expansion and contraction processes interact with resource supply ratios and requirement overlaps to determine the probabilities of coexistence among species [6]. Rarely are these processes stagnant, as the establishment of biogeographical limits among species is usually the outcome of complex intra and interspecific dynamics that are not alien to phylogenetic relationships: more related species are more likely to overlap in their ecological requirements [7]. These premises were the foundation of the contribution by Escoriza and Amat [8] to this Special Issue. In their article, they categorized the niches occupied by the largest Lacertid lizards in Southwestern Europe according to climate and vegetation cover, controlled for a mitochondrial-DNA based phylogeny [8]. Their results underscore the key role of climate structuring species segregation, as well as the influence of vegetation 
cover maintaining partition within the overlapped areas [8]. They also confirmed that overlapping tends to be greater in closely-related species [8].

A way to escape overlapping could be specialization, be it by evolving disparate diets, by segregating activity periods, or by establishing in habitats where interspecific competitors are scant or even absent [9]. That could be the case of high-elevation specialists. While lizards at high elevations may enjoy competition release [10], they may also face harsh conditions such as reduced temperature, shrunk activity-time window, food scarcity, and low partial pressure of oxygen [11]. Surviving these extreme conditions could require a series of changes at the morphological, behavioral, or physiological level. If these changes are not plastic, the reversibility of the elevational ascension could be at stake. In their article published in this Special Issue, Gangloff et al. [12] tested whether Iberolacerta bonnali lizards, whose distribution range is confined to high elevations in the Pyrenees, have adjusted their physiology to low partial pressure of oxygen to such extent that a transplant to low elevation conditions would affect other aspects of their physiology. Gangloff et al. [12] detected that, compared with conspecifics maintained within their natural elevation range, translocated lizards select lower body temperatures in a controlled experiment, and that their locomotor performance at high body temperatures is impaired, which is consistent with a physiological adaptation to low partial pressure of oxygen making them obligatory high-elevation dwellers.

In other instances, however, the occupation of such extreme habitats as high elevations is facultative, which clears the way for comparative research lines: due to the aforementioned elevational shifts in environmental conditions, species that exist along elevational gradients provide exceptional scenarios for a wide array of evolutionary hypotheses [13]. Although special priority has been given to those particular traits that allow organisms to cope with the varying parameters described, other features whose potential link with elevation is less obvious have received little attention. That is the case of coloration. Most research on elevational variation in ectotherms' coloration focuses on melanization as a mechanism to improve heating in low-temperature environments, in light of the thermal melanism hypothesis [14]. Meanwhile, other color traits have been virtually neglected. In the article they contributed to this Special Issue, Moreno-Rueda et al. [15] advanced the filling of this research gap by studying various correlates of ornamental coloration of Psammodromus algirus lizards in the context of a $2200 \mathrm{~m}$ elevational gradient in Sierra Nevada mountains (SE Iberian Peninsula). Moreno-Rueda et al. [15] detected that the number of blue lateral eyespots decreases with increasing elevation, whereas throat color becomes more saturated. Along with the presence of a color patch in the mouth commissures, these traits indicate larger heads, while throat saturation and the occurrence of colored commissures are greater in older individuals [15]. Additionally, males have more eyespots, whereas the presence of a colored commissure is less frequent in females [15]. These findings suggest that different color patches may convey redundant information whose perceptibility can be tuned to different environmental or social circumstances. With elevation, both biotic and abiotic factors change, as well as the perceptibility of signals, with weather conditions, depending on altitude. Different perceptibility depending on light or weather conditions may strengthen the importance of the redundant information contained in different signals [15].

While lizards possess some traits, such as coloration, that are universal, or at least widespread, in the animal kingdom, others are, if not unique, restricted to a few taxa. One example is autotomy, which involves the capability of some animals to self-detach a body part to escape a predator's grasp [16]. Although the appendage released is usually not essential for life, autotomy oftentimes comes with a series of costs that could negatively redound upon the individual's fitness [17]. In the case of lizards, numerous species possess autotomic tails, whose loss is foreseeably accompanied by a reduction in locomotor performance $[16,17]$. However, this rule could not be universal. In this Special Issue, Silva et al. [18] published a work that tests whether caudal autotomy affects locomotion in the South American lizard Micrablepharus atticolus, a semifossorial species with reduced 
limbs that combines undulant movements with trot-like locomotion. They discovered that sprint speed was not affected by autotomy in this species, whereas it varied among collection sites, and was dependent on body temperature, body mass, reproductive status, and the length of the regenerated portion of the tail [18]. The latter results largely confirm well-known predictors of locomotor performance in animals. However, the lack of effect of tail autotomy on sprint speed suggests a role for the locomotion mode and the microhabitat used.

To conclude, lizards constitute exciting investigation subjects in evolutionary ecology for innumerable reasons (e.g., [19]). Facts as disparate as the complex relationships between the habitats they occupy and their diversification history, the ecological patterns of spatial segregation among species, the physiological strategies permitting their occurrence in extreme habitats, the intricate components of visual communication, and the potential consequences of extreme antipredator strategies have been explored in this Special Issue. In doing so, it has accomplished its crucial goal of bridging and forwarding the knowledge on the diverse disciplines of ecology to which the study of lizards represents an outstanding contribution.

Author Contributions: Conceptualization, F.J.Z.-C. and M.C.; writing-original draft preparation, F.J.Z.-C.; writing-review and edition, F.J.Z.-C. and M.C. All authors have read and agreed to the published version of the manuscript.

Conflicts of Interest: The authors declare no conflict of interest.

\section{References}

1. Ananjeva, N.B. Current state of the problems in the phylogeny of squamate reptiles (Squamata, Reptilia). Biol. Bull. Rev. 2019, 9, 119-128. [CrossRef]

2. Reilly, S.M.; McBrayer, L.B.; Miles, D.B. Lizard Ecology; Cambridge University Press: New York, NY, USA, 2007.

3. Barton, N.H. On the completion of speciation. Philos. Trans. R. Soc. B 2020, 375, 20190530. [CrossRef] [PubMed]

4. Harvey, M.G.; Singhal, S.; Rabosky, D.L. Beyond reproductive isolation: Demographic controls on the speciation process. Ann. Rev. Ecol. Evol. Syst. 2019, 50, 75-95. [CrossRef]

5. Grismer, L.; Wood, P.L.; Poyarkov, N.A.; Le, M.D.; Karunarathna, S.; Chomdej, S.; Suwannapoom, C.; Qi, S.; Liu, S.; Che, J.; et al. Karstic landscapes are foci of species diversity in the world's third-largest vertebrate genus Cyrtodactylus Gray, 1827 (Reptilia: Squamata; Gekkonidae). Diversity 2021, 13, 183. [CrossRef]

6. Letten, A.D.; Ke, P.J.; Fukami, T. Linking modern coexistence theory and contemporary niche theory. Ecol. Monogr. 2017, 87, 161-177. [CrossRef]

7. Godsoe, W.; Jankowski, J.; Holt, R.D.; Gravel, D. Integrating biogeography with contemporary niche theory. Trends Ecol. Evol. 2017, 32, 488-499. [CrossRef] [PubMed]

8. Escoriza, D.; Amat, F. Habitat partitioning and overlap by large lacertid lizards in southern Europe. Diversity 2021, 13, 155. [CrossRef]

9. Costa-Pereira, R.; Araújo, M.S.; Souza, F.L.; Ingram, T. Competition and resource breadth shape niche variation and overlap in multiple trophic dimensions. Proc. R. Soc. B 2019, 286, 20190369. [CrossRef] [PubMed]

10. Comas, M.; Escoriza, D.; Moreno-Rueda, G. Stable isotope analysis reveals variation in trophic niche depending on altitude in an endemic alpine gecko. Basic Appl. Ecol. 2014, 15, 362-369. [CrossRef]

11. Jacobsen, D. The dilemma of altitudinal shifts: Caught between high temperature and low oxygen. Front. Ecol. Environ. 2020, 18, 211-218. [CrossRef]

12. Gangloff, E.J.; Spears, S.; Kouyoumdjian, L.; Pettit, C.; Aubret, F. Does hyperoxia restrict Pyrenean rock lizards Iberolacerta bonnali to high elevations? Diversity 2021, 13, 200. [CrossRef]

13. Tito, R.; Vasconcelos, H.L.; Feeley, K.J. Mountain ecosystems as natural laboratories for climate change experiments. Front. For. Glob. Chang. 2020, 3, 38. [CrossRef]

14. Clusella Trullas, S.; van Wyk, J.H.; Spotila, J.R. Thermal melanism in ectotherms. J. Therm. Biol. 2007, 32, 235-245. [CrossRef]

15. Moreno-Rueda, G.; Reguera, S.; Zamora-Camacho, F.J.; Comas, M. Inter-individual differences in ornamental colouration in a Mediterranean lizard in relation to altitude, season, sex, age, and body traits. Diversity 2021, 13, 158. [CrossRef]

16. Emberts, Z.; Escalante, I.; Bateman, P.W. The ecology and evolution of autotomy. Biol. Rev. 2019, 94, 1881-1896. [CrossRef] [PubMed]

17. Maginnis, T.L. The costs of autotomy and regeneration in animals: A review and framework for future research. Behav. Ecol. 2006, 17, 857-872. [CrossRef] 
18. Silva, N.A.; Caetano, G.H.O.; Campelo, P.H.; Cavalcante, V.H.G.L.; Godinho, L.B.; Miles, D.B.; Paulino, H.M.; da Silva, J.M.A.; de Souza, B.A.; Silva, H.B.F.; et al. Effects of caudal autotomy on the locomotor performance of Micrablepharus atticolus (Squamata, Gymnophthalmidae). Diversity 2021, 13, 562. [CrossRef]

19. Sinervo, B.; Livley, C.M. The rock-paper-scissors game and the evolution of alternative male strategies. Nature 1996, 340, $240-243$. [CrossRef] 